\title{
GCU
}

Glasgow Caledonian

University

University for the Common Good

\section{A case study investigation of academic library support for open educational resources in Scottish universities}

Thompson, Seth D.; Muir, Adrienne

Published in:

Journal of Librarianship and Information Science

DOI:

$10.1177 / 0961000619871604$

Publication date:

2020

Document Version

Author accepted manuscript

Link to publication in ResearchOnline

Citation for published version (Harvard):

Thompson, SD \& Muir, A 2020, 'A case study investigation of academic library support for open educational resources in Scottish universities', Journal of Librarianship and Information Science, vol. 52, no. 3, pp. 685-693. https://doi.org/10.1177/0961000619871604

\section{General rights}

Copyright and moral rights for the publications made accessible in the public portal are retained by the authors and/or other copyright owners and it is a condition of accessing publications that users recognise and abide by the legal requirements associated with these rights.

Take down policy

If you believe that this document breaches copyright please view our takedown policy at https://edshare.gcu.ac.uk/id/eprint/5179 for details of how to contact us. 


\title{
A case study investigation of academic library support for open educational resources in Scottish universities
}

\begin{abstract}
The aim of the research was to investigate why and how Scottish university libraries support Open Educational Resources (OER) and to assess their ability to provide support services for OER development and use within higher education institutions. There has been little research on the role of academic libraries in supporting OER in Scotland and previous research found that there is a lack of awareness of OER in Scottish higher education institutions and few have OER policies. The case study methodology therefore involved two Scottish academic libraries providing OER services. The libraries' motivation includes supporting teaching and learning and the development of educator digital skills and copyright knowledge. However, there are a number of barriers limiting the services the libraries are able to provide, particularly lack of human resources. The research confirmed the findings of previous research on the importance of institutional commitment, incentives for educator engagement, and understanding of copyright and licensing issues by educators and library staff.
\end{abstract}

\section{Keywords}

Open educational resources, open educational practices, higher education institutions, academic libraries, digital skills, copyright, licensing

\section{Introduction}

This paper discusses the results of an investigation to discover why and how Scottish university libraries support Open Educational Resources (OER) and to assess their ability to provide support services for OER development and use. UNESCO defines OER as "teaching, learning and research materials in any medium - digital or otherwise - that reside in the public domain or have been released under an open license that permits no-cost access, use, adaptation and redistribution by others with no or limited restrictions". This definition recognises the OER are not just in digital form and that "open" does not mean that OER are in the public domain. 
UNESCO (2012) has called on governments to openly license publicly funded educational materials for public use, having proposed (2011b) that OERs have the potential to improve curricula and teaching, reduce learning material costs and support educational transformation (2011a). The William \& Flora Hewlett Foundation (2019) has recognised the potential of OER for widening access to education and has provided financial support for OER development since 2002, aiming to help realise "mainstream adoption and effective use of openly licensed educational resources that provide students around the world greater access to a world class education" .

The proposed benefits of OER go beyond increased availability of educational resources and return on public investment. In 2011, Ehlers (2011) noted that initial OER initiatives focused on building repositories. He identified a shift in focus to a second phase of development where OER are part of more open educational practices. Ehlers (2011, p. 4) described open educational practices as those "which support the production, use and reuse of high quality open educational resources (OER) through institutional policies, which promote innovative pedagogical models, and respect and empower learners as coproducers on their lifelong learning path". Ehlers argues that openly accessible resources are necessary but not sufficient for truly open education. Butcher $(2015$, p. 36) has argued that the core of higher education in a transforming educational market will not be content, but the services that higher education institutions offer to students to guide and support them through their education, including assessment and accreditation.

The Scottish Government (2019) is committed to equal opportunity to enter and succeed in education. A number of actions address this policy goal, including free tuition fees and other financial support for less well-off students. The Scottish Government does not specifically endorse the potential of OER to support its educational policy. However, there is support for opening educational practices in the Scottish educational sector. Open Scotland, a voluntary cross sector organisation, published its Open Scotland Education Declaration in 2013. This built on UNESCO's (2012) Paris Declaration and called for the Scottish Government, the Scottish Funding Council (SFC) and the Scottish education sectors to endorse principles aimed at 'opening' resources. The Declaration included supporting social inclusion, widening participation and increasing engagement amongst the potential benefits. It also referred to the economic case of return on investment on public spending. 
Subsequently, the SFC funded the Opening Educational Practices in Scotland (OEPS) project, which discovered a generally low awareness of OER amongst Scottish HE educators (de los Arcos et al., 2016). The concept of open resources is in line with the library ethos of providing access to knowledge for all (Borchard and Magnuson, 2017; Smith and Lee, 2017; Ferguson 2017; Jansen and West, 2015), so academic libraries are an obvious candidate for supporting OER in higher education institutions. There has been little research investigating the role academic libraries could play in OER support in the Scottish context (de los Arcos, 2017, personal communication).

This research presents new knowledge in an under-researched field. It identified the small number of Scottish higher education institutions providing formal support for OER and involved in-depth case studies to answer the research questions: why and how Scottish university libraries support OER and how well are they able to provide support services for OER development and use. The research was limited in scope because of limited activity in the country, but it did identify factors affecting the ability of academic libraries to support OER and confirmed that they are similar to findings from studies in other countries. The conclusions on current and future ability of the academic library to provide this support for OER should have broader applicability.

\section{Background}

Bliss and Smith (2017) have written a brief history of the development of OER. They identify California State University's 1997 MERLOT educational resources repository as an early example of OER. There were other initiatives in the 1990s, including the Connexions open textbook platform and the University of Tübingen's timms online recorded lecture initiative. However, the most prominent early initiative was the 2001 Massachusetts Institute of Technology (MIT) OpenCourseWare (OCW) in 2001. The OCW publishes all institutional educational materials as online OER. At the time, Steven Lerman, the faculty chairman, was quoted as explaining the decision as follows "Selling content for profit, or trying in some ways to commercialize one of the core intellectual activities of the university seemed less attractive to people at a deep level than finding ways to disseminate it as broadly as possible." (Goldberg, 2001). This commitment to making all its course material freely available was a bold approach to fulfil the institution's goal of contributing to a shared intellectual commons but one the reputation and financial position of MIT made possible. The OpenCourseware initiative was initially supported financially by the William \& Flora Hewlett Foundation. The Foundation has since then supported many projects and initiatives 
that have been important to the OER movement, including the Open Education Consortium ${ }^{1}$, ISKME $^{2}$ and Creative Commons ${ }^{3}$. The growth of OER has been facilitated by open licensing. Open licences allow rights holders to authorise sharing and re-use of their intellectual property as they see fit. Creative Commons has made a major contribution by creating a set of licences, which are free to use, and a tool to help people identify which licence best suits their needs ${ }^{4}$. Creative Commons also helps people find openly licensed content ${ }^{5}$ by working with online content platforms.

Butcher (2015) has made a case for open educational resources and open educational practices. This learner-centred approach is very different to traditional higher education and it may take some time for higher education institutional cultures, policies and procedures to change sufficiently to embrace it. Cronin (2017) investigated open educational practices amongst educators who both do and do not utilise OER and found that those who did not engage cited a lack of confidence in the pedagogical value of open practices and an unwillingness to add to academic workloads. So truly open education may or may not become the norm over time. At the moment, despite the increase in availability of OER, there is still some lack of awareness or nervousness about the implications of making educational resources freely available. Despite the UK's Open University leading the way in opening up access to higher education and providing a portal of open education resources, the Higher Education Funding Council for England (HEFCE) funded a study between 2009 and 2012 to increase awareness and OER use in UK higher education (Mossley, 2013). In Scotland, the OEPS project discovered a generally low awareness of OER amongst Scottish HE educators (de los Arcos et al., 2016). Though de los Arcos et al. (2016) suggest that their findings may not be representative of the Scottish HE environment, they are similar to previous research (de los Arcos et al., 2015; de los Arcos et al., 2014). Respondents all identified a general lack of awareness in higher education as the largest perceived barrier to OER adoption (de los Arcos et al., 2016). Further perceived barriers included uncertainty over copyright permissions, how to use or adapt OER, difficulty locating OER and lack of institutional support. These findings were similar to those described by Butcher (2015). Though the responses to this survey may not be representative, they are not fundamentally different to previous studies (de los Arcos et al., 2015; de los Arcos et al., 2014), and survey findings of United States educators (Seaman and Seaman, 2017; Allen and Seaman, 2016).

\footnotetext{
${ }^{1}$ https://www.oeconsortium.org/

2 https://www.iskme.org/about-us

3 https://creativecommons.org/

${ }^{4}$ CC license chooser https://creativecommons.org/choose/

${ }^{5}$ CC Search tool https://search.creativecommons.org/
} 
In 2017, Cannell (2017) stated that only four Scottish universities had developed OER policies.

Jansen and West (2015), Borchard and Magnuson (2017), Smith and Lee (2017) and Ferguson (2017) have all identified the potential of academic library staff to play a vital role in developing teaching and learning through OER. Kleemeyer et al. (2010) pointed out the relevance of information professionals' skills, including searching, metadata creation, knowledge organisation, data storage, repository management, curation and preservation. They also referred to copyright knowledge, however other research has indicated that academic library staff may lack confidence in applying copyright knowledge in practice (Morrison and Secker, 2015). In a worldwide survey, albeit limited to 57 responses, of academic libraries and the role of librarians in OER initiatives Bueno-de-la-Fuente, Robertson and Boon (2012) found the involvement of librarians to be significant, with a librarian present in $75 \%$ of projects and considered a leading partner within $50 \%$ of projects. Similar to the findings of Kleemeyer et al. (2010), Bueno-de-la-Fuente, Robertson and Boon (2012, p.7) found that librarians performed roles associated with "description and classification, management, preservation, dissemination, and promotion of OER".

\section{Methods}

Previous research on OER and academic libraries has taken a case study approach (for example Kleemeyer et al., 2010; Hess et al., 2016; Goodsett et al., 2016). This paper reports the results from case study research that employed a qualitative methodology to explore the issues in context and in some depth. A multiple-case study design can provide additional analytical benefits compared with a single-case design (Yin, 2018). Cases provided evidence from multiple sources, and thus provided greater opportunities to compare, contrast and triangulate. An environmental scan of all eighteen Scottish higher education institutions identified two university libraries providing OER services (Cases $A$ and $B$ ). A third case was identified but it involved a dedicated OER service department that is not part of institutional library services, so it is not included here. An embedded design allowed for investigation of OER services approaches through the development of analytical sub-units (Yin, 2018). The library or department was the largest sub-unit, with smaller subunits, or components of the larger sub-unit, consisting of OER services, OER policy and academic librarians. 
Case $A$ is an academic library in a pre-1992 research-intensive university with an educational resource and OER repository. Case B is an academic library in a post-1992 university with a portfolio of OER services and openly available OER support documentation. The research employed a protocol, informed by the literature review, which set out in detail the procedures for each case to ensure reliability and replicability. Data was collected through documentary analysis and semi-structured interviews with library and other staff responsible for OER support.

A thematic analysis of documents provided background and context for each case. A request for relevant documents included institutional and department OER webpages, institutional and departmental OER strategy documents, departmental meeting minutes and departmental promotional, service and training materials. The thematic analysis also identified potential interview questions. Six semi-structured qualitative interviews were conducted: three each at Cases A and B. The semi-structured interview schedule (Appendix 1) acted as a fluid conversation guide, including open questions drawn from the literature and case documents.

Interviews and documents were initially analysed within cases. Codes used in interview transcripts were also applied to documents, with codes serving to integrate data (Bowen, 2009). Open coding allowed meaning to emerge from the data (Creswell, 2014) and codes from initial interviews and documents informed coding of later interviews and documents (Creswell, 2014). Codes were sorted into broader themes representing important aspects of the data (Braun and Clarke, 2006). Individual case reports were compiled based on these themes and these were then used to carry out the cross-case analysis reported in this article. The cross-case analysis highlighted replication or contrast in data (Yin, 2018).

\section{Findings}

The findings of the research are presented according to the sub-components of the research question. The reasons given by interviewees for library support of OER development and use are followed by details of how the libraries do this. The third section explores the various factors affecting the ability of the libraries to provide support, including issues affecting engagement with OER in each institution. Then findings of this study are placed within the broader context by comparing the data with the literature. 
Motivations for Supporting OER

Case A interviewees gave the following reasons for supporting OER: facilitating movement toward digital teaching and showcasing teaching resources, especially if the educator who created them is not research active. They also pointed out that library staff can help educators find resources, confirming the findings of Kleemeyer et al. (2010), Bueno-de-laFuente, Robertson and Boon, (2012), de los Arcos et al., (2016) and Hess et al. (2016). They can also assist with development of the skills required to use OER, reflecting the findings of de los Arcos et al. (2016). Case B interviewees thought that the library and library staff are well-placed to provide support because of the neutrality of the library space and the library staff's digital, information literacy and interpersonal skills.

How the Libraries Support OER

The case study services were built from the 'ground up' by the library through project funding. Both cases run educational repositories. Athenas and Havemann (2014) consider repositories as key to the success of the OER movement as they provide opportunities for educators to share, discover and re-use quality resources. However, Rolfe (2016) found that resources stored on external platforms received more site visits than those in institutional repositories (2016). There are very different levels of openness for Case A and B's repositories: Case A's default sharing setting is 'university only' whereas Case B's is 'worldwide'. While Case A's OER are not truly open, this is seen as an improvement on previous approaches. Reed's (2012) view is that though local sharing may not be entirely open, some engagement with openness is better than none whatsoever.

All interviewees expressed views similar to Reed's (2012) findings that providing training to enhance digital search skills, resource repurposing and open licensing awareness and understanding are critical in developing OER. Both of the case study OER services were supportive of educators but did not take responsibility for educators' resources as interviewees perceived that this approach could exacerbate digital skills gaps. Repository training is available on request, though not currently promoted at either case, and instructional documents are available. Interviewees at Case A discussed the need to persuade educators to share materials as OER, citing a number of reasons for educator reticence including proprietary attitudes toward resources and anxiety about peer judgements on the quality of the resources when shared. Winn in Cox (2013), Sefton (2010) 
and Beggan (2010) have also highlighted these issues as barriers to engagement with OER. Case B presented possible solutions to these problems, particularly educating teaching staff in Creative Commons (CC) licence use, thus ensuring that creators do not lose control of resources, whilst simultaneously reinforcing that OER can be modified. Therefore, educators searching for OER may do so with a mindset that resources may not be 'perfect' and adaptation may be required. At Case A, the library Learning Technologist has developed online copyright and CC licence training tools.

All of the interviewees discussed the need for collaboration with other individuals and departments in the university to develop and improve OER services. Bueno-de-la-Fuente et al. (2012), McGill et al. (2013) and Smith and Lee (2017) have also discussed the value and importance of collaboration in OER initiatives.

Institutional Culture, Policy and Educator Engagement

Mishra (2017) states that a lack of OER policy may be a barrier to the development and user of OER. Interviewees at Case A did not consider their lack of policy on OER as a hindrance, favouring an optional approach to avoid educator resentment. Case B has 'soft', nonmandated institutional policies that are consistent with UNESCO's (2011b) proposal for flexible policies. Institutional policies can encourage OER contributions (Corrall and Pinfield, 2014; Reed, 2012) as well as use (Nikoi and Armellini, 2012). A formal policy can also clarify institutional approaches to intellectual property rights ownership and management issues (Gadd and Weedon, 2017), and Case B's policies provide clear guidance in these issues. However, difficulties may arise if there is a lack of compatibility between OER philosophies and institutional culture (Friesen, 2009). Murphy (2013) suggests that a review of policies to consider social, cultural and economic OER issues may be required.

Case B adapted the University of Leeds' policy to suit their own needs, reflecting Cox and Trotter's (2016) assertion that the heterogeneity of HE environments requires OER policies that reflect the differences between institutions. Cox and Trotter (2016) state that institutional culture mediates the role policy plays in educator decision-making. There is evidence from Case $B$ that suggests that there may not be a unified institutional view on OER with some opposition at a senior level and a lack of educator agency. Case A interviewees also 
described mixed institutional feelings which are reflected in the repository services' default position of 'open to the university', which does not comply with the 'open to everyone' approach of OER philosophy. Ehler (2011) observes that educational practices are never completely closed or open and Wiley (2009) posits open practice is a continuous concept, and could be wide open, minimally open or somewhere in between. Although there is some evidence of educator engagement in the case studies in this research, all three highlighted a number of similar issues surrounding educators sharing materials as OER, including an overall lack of awareness. However, both cases did report an interesting development: educators were starting to use repositories but without any intention to create OER. The edShare system used in these institutions allows a wide variety of file types and sizes to be easily embedded within Virtual Learning Environments, which seems to be potentially of greater interest to educators than creating or adapting. An interviewee at Case B, reflecting on this, questioned whether their repository-based services had been created from library perspectives of curation and preservation and whether this approach meets the pedagogical needs of educators.

An aspect of institutional culture affecting engagement with OER and support services is intensity of research focus. In Case A's institution OER is regarded as of secondary importance. In Case B, the institutional focus on the Research Excellence Framework $(\mathrm{REF})^{6}$ was perceived to motivate academic staff to develop open access research outputs, with no equivalent driver for educational resources, as the Teaching Excellence Framework (TEF) does not mandate OER. Alevizou (2012), Jhangiani et al. (2016) and Cox (2013) have pointed out that a lack of professional incentives is a barrier to OER development. If there is little institutional or peer acknowledgment, there may be less incentive to develop or refine OER (Yuan et al., 2008). UNESCO recommend including OER within professional development programmes (2011b). Despite being generally supportive, Case B interviewees pointed out the difficulty of making the case for OER institutionally because of the lack of potential for income generation and the lack of external drivers for the adoption of open practice for educational resources. Rolfe (2012) found that a belief amongst educators that engaging with OER enhances career opportunities is a strong driver for sharing (Rolfe, 2012). Browne et al. (2010) found that educators do not want to invest time in OER if it will not enhance career prospects or if it is not fundamental to the future or university. These findings support UNESCO (2011b) suggestions on incorporating OER into educator professional development initiatives.

\footnotetext{
${ }^{6}$ The Research Excellence Framework is UK's systems for evaluating the quality of research carried out in higher education institutions https://www.ref.ac.uk/. The Teaching Excellence Framework has recently been introduced for measuring teaching quality.
} 
While interviewees in the two cases thought the library should support OER, they pointed out that doing so is not always straightforward. Cases $A$ and $B$ reported a number of challenging experiences with educators not inclined to get involved with OER. Educator sharing and borrowing attitudes may be 'entrenched in both professional and personal feelings and attitudes' (Rolfe, 2012: p.8). Anderson (2010) identifies two factors that influence educator attitudes to open practice: a natural instinct to share or not share; and the level of desire to be socially responsible toward their community. While sharing inclinations may not be readily modified, they may be influenced by cultural surroundings, including where open practice is valued institutionally (Anderson, 2010).

Barriers affecting the Ability of Academic Libraries to Provide OER Support Services

A critical OER issue is how to provide adequate and sustainable resourcing of support services when the objective is to make educational materials freely available (Wiley and Gurrell, 2009). Mulder (2013) stated that institutional budgets are key to OER and both case studies highlighted similar concerns. Both cases received library project funding to develop a repository and support services. They do not have ongoing additional financial support. Both cases recognise the importance of advocacy in promoting understanding of OER, acknowledging the lack of understanding of OER amongst educators as found by de los Arcos et al. (2016). However, lack of staff time has an impact on promoting awareness, which is also recognised by Smith and Lee (2017) and Okamoto (2013). Staffing levels at Case $A$ affect OER services as this is a minor part of staff roles. At Case $B$, interviewee views differed on the strength of support services, being described as flexible by one interviewee and as reactive to enquiries by another. Lack of staff time was also an issue at Case B: there is a permanent staff member with responsibility for OER services, but this is just one among a number of competing responsibilities.

Cases $A$ and $B$ provide repositories that host both OER and non-OER materials. Repository materials are accompanied by licence statements to facilitate re-purposing, but this may not be sufficient to ensure lawful use of all materials in the repositories. To avoid any copyright and licensing issues arising from inappropriate re-use of material, educators need to know enough about these issues to take appropriate decisions. Interviewees at both case study libraries agreed that educators should take responsibility for ensuring that OER are correctly 
licensed. Case B makes this point explicit in a policy statement. De los Arcos et al. (2016) found that a lack of understanding of permissions to use or modify resources was a barrier for educators who were aware of OER. All cases reported that copyright is a challenging issue and that there is not a high level of understanding of copyright, $\mathrm{CC}$ licences and permissions to adapt OER amongst educators. The case study libraries provide information and advisory services, but staff are not qualified to deliver legal advice.

Butcher (2015) discussed the relationship between knowledge of open licensing and fear of loss of control of resources. Case B said that lack of knowledge or understanding was perceived to contribute to fear of loss of control of resources. These negative views are echoed in Morrison and Secker's (2017) view that copyright is seen as a problem in elearning. However, the cases provided evidence of some collaborative working with educators to develop copyright understanding, including the use of games (Case A) and an online interactive copyright flowchart. Case B commented on the need for good copyright and licensing practices from the creation stage of OER development to avoid difficulties and the need for time-consuming retrospective action. This approach reflects Morrison and Secker's (2017) observation that librarians who engage with copyright as an opportunity are more likely to become involved with projects in the initial phases and not join copyright as a problem solver.

Cases $A$ and $B$ are two of a small, but growing number of UK institutions that possess institutional OER repositories which utilise edShare software (Terrell, 2016). EdShare is an open source platform, which facilitates platform development based on user community contributions (Terrell, 2016). This approach has incorporated learning from the success of social sharing and the removal of traditional repository restrictions (Terrell, 2016). Ferguson (2017) states that for academic libraries to continue to participate in OER conversations, they must adapt to the needs of departments, staff and students. Rolfe's (2016) arguments suggest that institutional repositories may not provide the most effective OER access point, with external websites and SEO potentially broadening exposure and access. This raises the question of whether library OER services should move away from traditional library curation strategies, such as in-house storage, and focus on other forms of support. On the other hand, institutional repositories may be better able to ensure the persistence and preservation of resources than commercial platforms. 


\section{Conclusion}

The aim of the research was to investigate why and how Scottish university libraries support Open Educational Resources (OER) and to assess their ability to provide support services for OER development and use. There is evidence of a lack of awareness of OER and limited activity in creating and using OER in Scottish universities. Two academic library services providing support for OER were identified. The research found that the library staff are committed to supporting the creation and use of OER in their institutions and felt that the library and its staff were well-placed to provide support services in terms of knowledge and skills. Despite being generally supportive of OER, interviewees pointed out challenges in advocating for and supporting OER within their institutions because of a lack of drivers for the adoption of open practices and OER within their institutions. Both libraries were based in institutions where research outputs are prioritised over OER and there is some lack of awareness and reluctance to engage with OER amongst educators. Some educators are using the repositories to locate OER but are not creating them. Both libraries recognised the need for awareness raising and for the development of the knowledge and skills required by educators to reduce their concerns about OER and allow them to create and use OER without infringing copyright law.

Both libraries provided repository-based services to provide access to OER, licence information and also to act as a showcase for the OER produced by educators in their institutions. There was evidence at one institution of some reflection on whether this approach was best suited to the needs of educators. Support does go beyond maintaining repositories and repository-related training relating in both libraries. The libraries provided information, advice and training relevant to OER, including digital skills and copyright and licensing. However, lack of resources reduces the levels of support that the libraries are able to provide. Staff do not have enough time to undertake advocacy activities or deliver a regular programme of training. Anxiety around ownership and control of resources appears to be a serious barrier to educator engagement with OER. The two libraries address this in various ways, including the development of online tools to help educators understand the copyright and licensing issues that arise from what they would like to do with resources. Knowledge and skills about copyright can also be a barrier for library staff (Schmidt and English 2015; Fernández-Molina, Moraes, and Guimarães, 2017). Morrison and Secker's (2015) survey on librarian copyright literacy found that UK library professionals were more confident of their level of knowledge than colleagues in other countries and that UK institutions were more likely to employ an individual with responsibility for copyright. However, UK respondents did express some anxiety about dealing with copyright issues and 
a desire for more practical application of copyright law in academic studies and professional training.

The findings of the research show that the two Scottish university libraries want to support OER and are providing OER-related services in their institutions. However, there are barriers that affect their ability to do so. Academic libraries can potentially provide support services, but institutional culture and policy would have to encourage and support OER with sufficient resources to allow the libraries to do more. External drivers, such as the inclusion of OER in teaching excellence assessments, may also be necessary so that higher education institutions have reputational and financial incentives to support OER and open practices. In making the case for OER, Butcher (2015, p. 41) has suggested human resource policy change to incentivise creating, adapting and sharing education resources. Butcher (2015) also recommends the development of copyright policies and awareness raising of copyright and licensing issues amongst educators to help dispel anxieties around control of intellectual property and allow educators to understand the copyright and licensing issues involved in any OER they create or use.

\section{References}

Alevizou P (2012) Open to interpretation? Productive frameworks for understanding audience engagement with OER. In: Cambridge 2012: Innovation and Impact - Openly Collaborating to Enhance Education, a Joint Meeting of OER12 and OpenCourseWare Consortium Global 2012, Cambridge, UK, 16-18 April 2012. Available at: http://oro.open.ac.uk/33452/ (Accessed 20 March 2019).

Allen IE and Seaman J (2016) Opening the textbook: educational resources in U.S. Higher Education, 2015-16. Babson Survey Research Group: Pearson.

Anderson MH (2010) To share or not to share: is that the question? EDUCAUSE Review, 45(4): 40-49.

Athenas J. and Havemann L. (2014) Questions of quality in repositories of open educational resources: a literature review. Research in Learning Technology, 22: 1-13.

Beggan, A. (2010). Exploring institutional attitudes to open learning, the BERLiN experience.Paper presented at OER10, Cambridge, 22-24 March 2010. Available at: http://www.ucel.ac.uk/oer10/programme.html (accessed 10 June 2019). 
Bliss TJ and Smith, M (2017). A brief history of open educational resources. In: Jhangiani RS and Biswas-Diene R (eds) Open: The Philosophy and Practices that are Revolutionizing Education and Science. London: Ubiquity Press: 9-27.

Borchard L and Magnuson L (2017) Library leadership in open educational resource adoption and affordable learning initiatives. Urban Library Journal, 23(1), Article 1.

Bowen GA (2009) Document analysis as a qualitative research method. Qualitative Research Journal, 9(2): 27-40.

Braun V and Clarke V (2006) Using thematic analysis in psychology. Qualitative Research in Psychology, 3(2): 77-101.

Bueno-de-la-Fuente G, Robertson RJ and Boon S (2012) The roles of libraries and information professionals in Open Educational Resources (OER) initiatives: survey report. JISC Cetis.

Cannell, P (2017) OEPS: final project report. Edinburgh: Opening Educational Practices in Scotland.

Corrall, S and Pinfield, S (2014) Coherence of "open" initiatives in higher education and research: framing a policy in agenda. In: iConference 2014 Proceedings. Berlin, Germany, 4-7 March 2014: pp. 293-313.

Cox, G (2013) Researching resistance to open education resource contribution: an activity theory approach. E-Learning and Digital Media, 10(2): 148-159.

Cox, G and Trotter, H (2016) Institutional culture and OER policy: how structure, culture, and agency mediate OER policy potential in South African universities. International Review of Research in Open and Distributed Learning, 17(5): 147-164.

Cronin, C (2017) Openness and praxis: exploring the use of open educational practices in higher education. International Review of Research in Open and Distributed Learning, 18(5): 15-34.

De los Arcos, B, Cannell, P and Mcillwhan, R (2016) Awareness of open educational resources (OER) and open educational practice (OEP) in Scottish higher education institutions: survey results: interim report. Edinburgh: Opening Educational Practices in Scotland.

De los Arcos, B, et al. (2014) OER evidence report 2013-2014. OER Research Hub. Available from: http://oro.open.ac.uk/41866/ (accessed 20 March 2019).

De Los Arcos, B, et al. (2015) OER Research Hub data 2013-2015: educators. OER Research Hub. Available from: http://oro.open.ac.uk/47931/ (accessed 17 December 2017). 
Ehlers, U-D (2011) Extending the territory: from open educational resources to open educational practices. Journal of Open, Flexible and Distance Learning, 15(2): 1-10.

Ferguson, CL (2017) Open educational resources and institutional repositories. Serials Review, 43(1): 34-38.

Fernández-Molina, J-C, Moraes, JBE and Guimarães, JAC (2017) Academic libraries and copyright: do librarians really have the required knowledge? College \& Research Libraries, 78(2): 241-259.

Friesen, N (2009) Open educational resources: new possibilities for change and sustainability. The International Review of Research in Open and Distance Learning, 10(5). DOI: https://doi.org/10.19173/irrodl.v10i5.664

Gadd, G and Weedon, R (2017) Copyright ownership of e-learning and teaching materials: policy approaches taken by UK universities. Education and Information Technologies, 22(6): 3231-3250.

Goldberg, C (2001). Auditing Classes at M.I.T., on the Web and Free. The New York Times, April 4. Available from: https://www.nytimes.com/2001/04/04/us/auditing-classes-at-mit-onthe-web-and-free.html (accessed 4 June 2019).

Goodsett, M, Loomis, B and Miles, M (2016) Leading campus OER initiatives through libraryfaculty collaboration. College and Undergraduate Libraries, 23(3): 335-342.

Hess, JI, Nann, AJ and Riddle, KE (2016) Navigating OER: the library's role in bringing OER to campus. The Serials Librarian, 70(1-4): 128-134.

Jhangiani, R, Pitt, R, Hendricks, C, et al. (2016) Exploring faculty use of open educational resources at British Columbia post-secondary institutions. BCcampus research report. . Victoria, BC: BCcampus. Available from: https://bccampus.ca/files/2016/01/BCFacultyUseOfOER_final.pdf (accessed 20 March 2019).

Kleemeyer, P, Kleinman, M and Hanss, T (2010) Reaching the heart of the university: libraries and the future of OER. In: Open ED 2010 Proceedings. Barcelona, Spain, 2-4 November 2010, UOC, OU, BYU: 241-250.

McGill, L, Falconer, I, Dempster, JA, et al. (2013) Journeys to open educational practice: UKOER/SCORE review final report. . JISC. Available from: https://oersynth.pbworks.com/w/page/60338879/HEFCE-OER-Review-Final-Report (accessed 20 March 2019). 
Mishra, S (2017) Open educational resources: removing barriers from within. Distance Education, 38(3): 369-380.

Morrison, C and Secker, J (2015) Library and Information Research, 39 (121): 75-97.

Morrison, CM and Secker, J (2017) Understanding librarians' experiences of copyright: findings from a phenomenographic study of UK information professionals. Library Management, 38(6/7): 354-368.

Mossley, D (2013) Open educational resources and open education. York: The Higher Education Academy.

Mulder, F (2013) The LOGIC of national policies and strategies for open educational resources. The International Review of Research in Open and Distance Learning, 14(2): 97105.

Murphy, A (2013) Open educational practices in higher education: institutional adoption and challenges. Distance Education, 34(2): 201-217.

Nikoi, S and Armellini, A (2012) The OER mix in higher education: purpose, process, product, and policy. Distance Education, 33(2): 37-41.

Okamoto, K (2013) Making higher education more affordable, one course reading at a time: academic libraries as key advocates for open access textbooks and educational resources. Public Services Quarterly, 9(4): 267-283.

Open Scotland (2013) Open Scotland education declaration. Available from: http://declaration.openscot.net/ (accessed 4 June 2019).

Reed, P (2012) Awareness, attitudes and participation of teaching staff towards open content movement in one university. Research in Learning Technology, 20(4): Available from: https://www.learntechlib.org/p/167813/ (accessed 20 March 2019).

Rolfe, V (2012) Open educational resources: staff attitudes and awareness. Research in Learning Technology, 20(1), 14395.

Rolfe, V (2016) Web strategies for the curation and discovery of open educational resources. Open Praxis, 8(4): 297-312.

Scottish Government (2019) Policy: universities. Available from: https://www.gov.scot/policies/universities/ (accessed 4 June 2019).

Seaman, JE and Seaman, J (2017) Opening the textbook: educational resources in U.S. Higher Education, 2017. Babson Survey Research Group: Pearson.opal 
Sefton, P (2010) My fave two reasons not to release opencourseware. 12 August 2010. Available from: http://ptsefton.com/2010/08/12/my-fave-two-reasons-not-to-releaseopencourseware.htm (accessed 20 March 2019).

Smith, B and Lee, L (2017) Librarians and OER: cultivating a community of practice to be more effective advocates. Journal of Library and Information Services in Distance Learning, 11(1-2):106-122.

Terrell, K (2016) Repositories for OERs, they're not dead yet. 28 October 2016. Available from: https://kellyaterrell.wordpress.com/2016/10/28/repositories-for-oers-theyre-not-deadyet/ (accessed 20 March 2019).

UNESCO (2011a) A basic guide to open education resources (OER). Paris: UNESCO and Commonwealth of Learning.

UNESCO (2011b) Guidelines for open educational resources (OER) in higher education. Paris: UNESCO and Commonwealth of Learning.

UNESCO (2012) 2012 Paris OER Declaration. 2012 Paris: UNESCO. Available from: http://www.unesco.org/new/fileadmin/MULTIMEDIA/HQ/CI/CI/pdf/Events/Paris\%200ER\%20 Declaration.pdf (accessed 20 March 2019).

William \& Flora Hewlett Foundation (2019) Open educational resources. Available from: https://hewlett.org/strategy/open-educational-resources/ (accessed 4 June 2019).

Yin RK (2018) Case study research and applications: design and methods. $6^{\text {th }}$ ed. Thousand Oaks: SAGE.

Yuan L, MacNeill S and Kraan W (2008) Open educational resources - opportunities and challenges for higher education. JISC Cetis. 


\section{Appendix 1 Interview Questions}

\section{Introduction}

- Introduce yourself as the interviewer

- Reiterate informed consent- explain right to withdraw at any time, no personal data will be recorded. Within the dissertation, interviewees will be referred to by a case interviewee number (for example: Case A, interviewee 1).

We're here today to talk about Open Educational Resources (OER) and academic libraries...

- Outline conversational approach of a case study interview (Yin 2018)

- Outline the line of enquiry- OER, interviewee's department and OER, interviewee's institution and OER

- Inform the interviewee that the researcher will use open questions and may probe responses/ask interviewee to elaborate

\section{Questions}

Note to researcher:

Consider Aim and Objectives 1-4 throughout interview

Research aim:

To examine how Scottish HEl academic libraries support OER, and investigate if the academic library may be a viable support structure for OER within Scottish HEls.

\section{Research Objectives:}

1. Discover why academic libraries may wish to support OER within their institutions

2. Identify any potential factors affecting academic libraries ability to support OERs in their institutions

3. Critically evaluate how academic libraries are currently supporting OER

4. Formulate recommendations on issues relating to academic libraries' current and future ability to support OER

1. ICE BREAKERS (general awareness of OER)

a. What does Open Educational Resources or OER mean to you?

PROBE: How did you come to thinking this?

b. How have you been involved with OER?

2. Do you think academic libraries or departments within HEls might want to support OER (Objective 1)?

PROBE: How did you come to thinking this?

3. What does your department do with OER (Objective 1 and 2)?

PROBE: why do you think your department does this? 
PROBE: how does your department do this?

4. Does anything challenge, hinder or obstruct your department in delivering OER services/initiatives (Objective 2)?

PROBE: How does this challenge your department?

PROBE: Why do think this is a challenge or obstruction?

5. Does anything enable, help, drive or facilitate your department in delivering OER services/initiatives (Objective 2)?

PROBE: How is this an enabler or a help to your department?

PROBE: Why do you think this helps or enables?

6. OER can be a broad ranging topic, is there anything that your department doesn't do with OER (Objective 2,3,4)?

PROBE: Why do you think your department does not do this?

7. How does your institution view OER (Objective 1 and 2)?

PROBE: Why do you think this is?

\section{Thank interviewee}

Thank the participant for their responses, for taking part in the interview, and acknowledge the time they have given to the interview and the dissertation project. 
